\section{A truly space-saving solution}

You can rely on Clark Dental to offer state-of-the-art treatment centres from Sirona, including the Intego Ambidextrous.

Available as a TS version with hanging hoses or a CS version with whip arms, this cuttingedge treatment centre is optimised for both left- and right-handed dentists. It features an intelligently designed rotating mechanism that enables you to convert the treatment centre in just 15 seconds. This can be done without compromising available space, as the

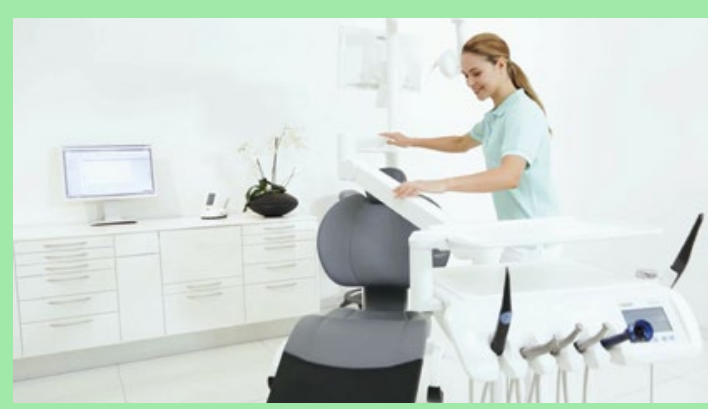
Intego Ambidextrous is not only compact, but also offers a wide range of integrated features.

To explore the full list of equipment options for the Intego Ambidextrous, contact the friendly team at Clark Dental on 01268733 146, emailinfo@ clarkdental.co.uk or visit www. clarkdental.co.uk.

\title{
Step into the future, today
}

Essential equipment maintenance can be a real stress and strain on your time in practice.

So why not step into the future of maintenance by choosing Total Air Care from

DentalAir?

A comprehensive approach that covers all of your dental air compressor needs, signing up to this package is priced from as little as $£ 14.95$ per week and includes the installation of a new, oil-free dental air compressor. With Total Air Care you can rest assured that your dental air compressor will remain compliant and provide sterile air for use throughout your practice. Plus, should anything ever go wrong, you know it will be up and running again in no time thanks to our swift, national breakdown service.

Find out more by contacting DentalAir at info@dentalair.com or call 0800975 7530 .

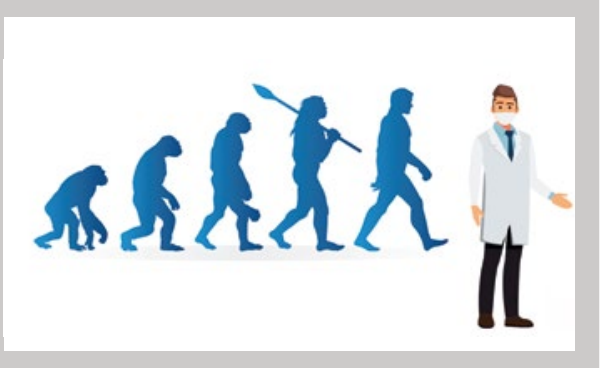

\section{Clean and disinfect in one minute}

With a one-minute contact time, OPTIM 1 wipes are ideal for infection control in the dental practice.

Combining a cleaner and disinfectant, a single OPTIM 1 wipe will cover a larger surface area than most other products available.

OPTIM 1 wipes have been tested and passed for all major dental chair upholstery

for added peace of mind. If you are concerned about the environmental impact, OPTIM 1 wipes are alcohol-free with hydrogen peroxide as the active ingredient, which breaks down into water and oxygen. They are also supplied in type 2 recyclable containers.

For information about OPTIM 1, visit https://www.scican. com/eu/products/cleaners-disinfectants/optim-1/.

\section{Waterflossing is}

\section{a winner}

The Waterpik
Water Flosser
is safe and
effective for
almost all
patients. It
is clinically
proven to
be up to
50\% more
effective
at reducing
gingivitis, up to 93\% more effective for
reducing bleeding and can remove up to
29\% more plaque than string floss.
Also, the Waterpik Water Flosser
delivers better results than string floss for
patients with orthodontic appliances and
dental implants. Plus, there is a model to
suit everyone too - take a closer look at the
extensive Waterpik product range now.
For more information on Waterpik
products please visit www.waterpik.
co.uk or book a Waterpik Professional
Lunch and Learn at www.waterpik.co.uk/
professional/lunch-learn/

\section{Remove the headache}

The first tax return of the year might be out of the way but with another one looming some of you might be wondering if there's a way to remove the headache and make the process easier. You'll be pleased to know that there is - give the responsibility to accountants4dentists.

Highly experienced and renowned for providing a first-class professional service to dentists, the team is well equipped to take care of all your accounts preparation and tax compliance, giving you one less thing to worry about. Should you desire, an accountant can even take care of your book-keeping and help you plan for the year ahead.

To find out more how the team could help with your upcoming tax return and beyond, contact accountants4dentists on 08453455060 or 0754 DENTIST, via email info@4dentistsgroup.com or visit www.4dentistsgroup.com. 